\title{
Fatal pesticides poisoning in Morocco (2000-2005)
}

\section{Intoxications mortelles aux pesticides au Maroc (2000-2005)}

\author{
Mina Ait El Cadi ${ }^{\star}$, Aziza Mezzane, Bouchra Meddah, Youssef Khabbal, Larbi Idrissi \\ Laboratory of Forensic Toxicology, National Institute of Health Morocco, Morocco
}

\begin{abstract}
Introduction: Acute poisoning by pesticides become more and more frequent, it's an important cause of morbidity and mortality worldwide. The aim of our study was to determine the epidemiological profile of fatal pesticide poisoning deaths in Morocco between 2000 and 2005. Materials and methods: A retrospective study, covering the period from January 2000 to December 2005 was based on database of Laboratory of Forensic Toxicology in the National Institute of Health in Morocco included all positives results in pesticides analysis. Cases were analyzed according to the following criteria: gender, age, origine, poisoning type and class of pesticide. Results: In the period of study, from total of 3104 analysis performed in the laboratory, 130 cases $(4.2 \%)$ were related with fatal pesticides poisoning deaths which were classified as a suicide in $23.1 \%$ cases, as an uncertain in $75 \%$ and accidental in $1.5 \% .51 \%$ of cases were related to males and $48 \%$ to females. The most represented city was Rabat with 55 cases (42.3\%). Insecticides (organophosphorus, organochlorine and carbamates) were the most frequent cause of fatal pesticides poisoning (75.2\%), followed by aluminum phosphide $(21.5 \%)$, one case of pyrethroid and one case of coumarinic anticoagulant were found. Conclusion: In spite of the effort made in the rules of pesticides in Morocco, the government must develop a strong system which can attribute to prevent this poisoning.
\end{abstract}

Key words: Pesticides, acute poisoning, organophosphorus, carbamates, rat poisons

\begin{abstract}
Résumé - Introduction : Les intoxications aigües par les pesticides sont devenues de plus en plus fréquentes. Elles représentent une importante cause de morbidité et de mortalité à travers le monde. L'objectif de notre travail était de tracer un profil épidémiologique des intoxications mortelles par les pesticides au Maroc sur la période entre 2000 et 2005. Matériel et méthodes : Étude rétrospective recouvrant la période de janvier 2000 à décembre 2005, fondée sur les donnés toxicologiques du laboratoire de Toxicologie à l'Institut National d'Hygiène (Maroc). Les cas ont été analysés selon les critères suivants : sexe, âge, origine, type d'intoxication et classe des pesticides incriminés. Résultats : Sur la période étudiée, parmi les 3104 analyses effectuées au laboratoire, 130 cas (4,2\%) sont reliés aux intoxications mortelles aux pesticides ; $23,1 \%$ des intoxications aux pesticides sont volontaires, $75 \%$ sont d'origine indéterminée et seulement $1,5 \%$ sont accidentelles. On retrouve $51 \%$ d'hommes et $48 \%$ de femmes. La ville la plus représentée est Rabat avec 55 cas $(42,3 \%)$. Les insecticides (organophosphorés, organochlorés et carbamates) sont les plus incriminés dans ces intoxications $(75,2 \%)$ suivis de phosphure d'aluminium $(21,5 \%)$. Un cas d'intoxication aux pyréthrinoïdes et un cas de raticide coumarinique sont retrouvés. Conclusion : Malgré les efforts fournis dans la réglementation des pesticides au Maroc, le gouvernement doit développer en collaboration avec tous les organismes concernés un système puissant pour la prévention de ces intoxications.
\end{abstract}

Mots clés : Pesticides, intoxications aigues, organophosphorés, carbamates, raticides

Reçu le 22 juin 2008, accepté après modifications le 17 décembre 2008

Publication en ligne le 31 janvier 2009

\section{Introduction}

Pesticides are defined as any substance or mixture of substances intended for preventing, destroying, repelling or mitigating any pest [1]. They are used in most countries around the world to protect agriculture and horticultural corps against damage; they are also used as domestic insecticides [2]. Acute

\footnotetext{
^ Correspondence: Ait El Cadi Mina, Tél.: +212.66.08.91.08 /

$+212.37 .77 .19 .02 /+212.37 .77 .19 .65$, Fax: +212.37.77.20.67 /

+212.37.68.16.53, macadiph@yahoo.fr
}

poisoning by pesticides becomes more and more frequent. It is an important cause of morbidity and mortality worldwide. According to WHO report, it has been estimated around three million severe cases of acute pesticides poisoning and more than 200000 deaths occurred each year [3-6]. In Morocco which is an agriculture country, there are a few studies which evaluate pesticides morbidity and mortality.

The aim of our study was to determine the epidemiological profile of fatal pesticide poisoning in Morocco between 2000 and 2005. 


\section{Materials and methods}

A retrospective study, covering the period from January 2000 to December 2005. The study was based on autopsies samples sent to the Laboratory of Forensic Toxicology in the National Institute of Health in Morocco. Cases were selected from the forensic toxicology database including all positives results in pesticides analysis. Cases were analyzed according to the following criteria: gender, age, origin, poisoning type and class of pesticide. The recorded cases were classified according to the International Classification of Diseases (ICD). Results were expressed with average \pm s.e.m for quantity parameters. Methods used to determine pesticides in human samples were:

\section{- Gas chromatography spectrometry (GC-MS):}

The GC-MS system consisted of a Varian CP-3800 Saturn 2000 equipped with a Varian 8200 auto sampler and a class GC/MS Varian software. The capillary column was DB5, $30 \times 0.25 \mathrm{~m} \times 0.25 \mu \mathrm{m}$. The injector was set at a temperature of $250{ }^{\circ} \mathrm{C}$ and used in the splitless mode. The carrier gas was helium and its flow rate was $1 \mathrm{~mL} / \mathrm{min}$. The oven temperature was ranged from $70{ }^{\circ} \mathrm{C}$ to $160{ }^{\circ} \mathrm{C}$ at $2 \mathrm{~min}$ and $250{ }^{\circ} \mathrm{C}$ at $10 \mathrm{~min}$. Ionization was performed in the electron impact mode at $70 \mathrm{eV}$. GC/MS used to analyse organochlorine and pyrethroid insecticides.

\section{- Gas chromatography (GC):}

The CPG system consisted of a Shimadzu GC-17A (ver. 3) equipped with VLMEC1Boyer auto sampler and Class GC-10 software. A Chromopack capillary column CP-SIL8 CB was used. The injector used in the splitless mode, its temperature began with $80^{\circ} \mathrm{C}$ and then it increased by $180{ }^{\circ} \mathrm{C} / \mathrm{min}$ to arrive at $240{ }^{\circ} \mathrm{C}$. Temperature program of the column oven was $80^{\circ} \mathrm{C}$ for $2 \mathrm{~min}$, followed by the increasing with $10^{\circ} \mathrm{C} / \mathrm{min}$ at $260^{\circ} \mathrm{C}$ in $15 \mathrm{~min}$. Helium carrier gas supplied in constant flow mode with $2.4 \mathrm{~mL} / \mathrm{min}$. The NPD detector was used, its temperature base set at $300{ }^{\circ} \mathrm{C}$. GC was used to analyse organophosphorus.

- High performance liquid chromatography (HPLC) system:

The HPLC used was Perkin Elmer series 200 equipped with Perkin Elmer series 200 injector, auto sampler, software and a diode array detector. The column used was Varian RES E2UT $5 \mu$ C8 90R250 $\times 4.605 \mu$. The injection volume was $20 \mu \mathrm{L}$. The elution was in isocratic mode with the flow rate of $1 \mathrm{~mL} / \mathrm{min}$. The acetonitril /water in 50/50 (v/v) were used as a mobile phase. HPLC was used to analyse carbamates.

\section{- Colorimetric reactions:}

Aluminum phosphide was detected in blood by a chemical reaction having for principle the reduction of the silver nitrate by the phostoxin ${ }^{\circledR}$ which colors strips in black.

Coumarinic anticoagulants were detected by chromatography on thin layer; the mobile phase consists of ether, benzene, acetone and acetic acid (60/50/10/01) and revelation was made by the UV light.

\section{- Extraction of pesticide from samples.}

The samples used were blood and gastric content. The first extract was made with dichloromethane with anhydrous sodium sulphate. After filtration, the extract obtained was evaporated in a rotary evaporator to dryness. The dry extract was dissolved in $40 \mathrm{~mL}$ of hexane and cleaned up first by four extractions liquid-liquid, each extraction was made by $40 \mathrm{~mL}$ of acetonitril-hexane $(\mathrm{v} / \mathrm{v})$. The acetonitril extract obtained was evaporated until $3 \mathrm{~mL}$ and was cleaned up in a Florisil column. This extract was divided into two fractions; one fraction was eluted by petroleum ether and was used to detect organophosphorus and organochlorine. The second fraction was eluted by acetonitril and was used to detect carbamates. The extract obtained in each case was evaporated again until $1 \mathrm{~mL}$ of volume.

\section{Results}

In the period between January 2000 to December 2005, from total of 3104 analysis performed in the laboratory, 130 cases $(4.19 \%)$ were related with fatal pesticides poisoning death.

Fatal pesticides intoxications were classified as a suicide in $23.1 \%$, as an uncertain in $75 \%$ cases and only $1.5 \%$ fatal poisonings were accidentals. The average of age was $28 \pm 15$ years old. The age profile of the recorded poisoning deaths is presented in figure 1 . The highest frequency of pesticide poisoning $(40.8 \%)$ was found related to the age group 20-39 years old. The difference between gender in pesticides fatal poisoning was small, $51 \%$ of males and $48 \%$ of females. This difference may be explained by the predominance of voluntary poisoning which recorded to females. Some papers confirm our result [7]. The range age of male cases was 30-39, for the female case the range was 0-19 and 20-39 (figure 2).

Samples sent from the majority of Moroccan cities including urban areas and rural regions; however the most represented city was Rabat with 55 cases $(42.3 \%$ ) (figure 3 ). That may be explained by the time of storage of samples from other cities. Our data showed that insecticides were the most frequent cause of fatal pesticides poisoning $(75.2 \%)$, followed by aluminum phosphide (21.5\%) (figure 4). In insecticides, organophosphorus were the most frequent $(55.4 \%)$, followed by carbamates $(15.4 \%)$ and organochlorine $(4.6 \%)$, one case of pyrethroid and one case of coumarinic anticoagulant were found.

\section{Discussion}

The incidence of pesticide poisoning in Morocco in the period between 2000 and 2005 was $4.19 \%$, it can be compared with other series [8-10]. However, there is a lack of systematic studies and declaration in Morocco especially in rural areas, this lack makes the discussion of our results difficult and may underestimate the number of fatal pesticides poisonings. Our data showed that pesticides are commonly used for suicide. This result is in accordance with previous studies [11-13]. In fact, in Sri Lanka $90 \%$ of suicides are due to deliberate pesticide ingestion [14], the WHO report that pesticides are now the 


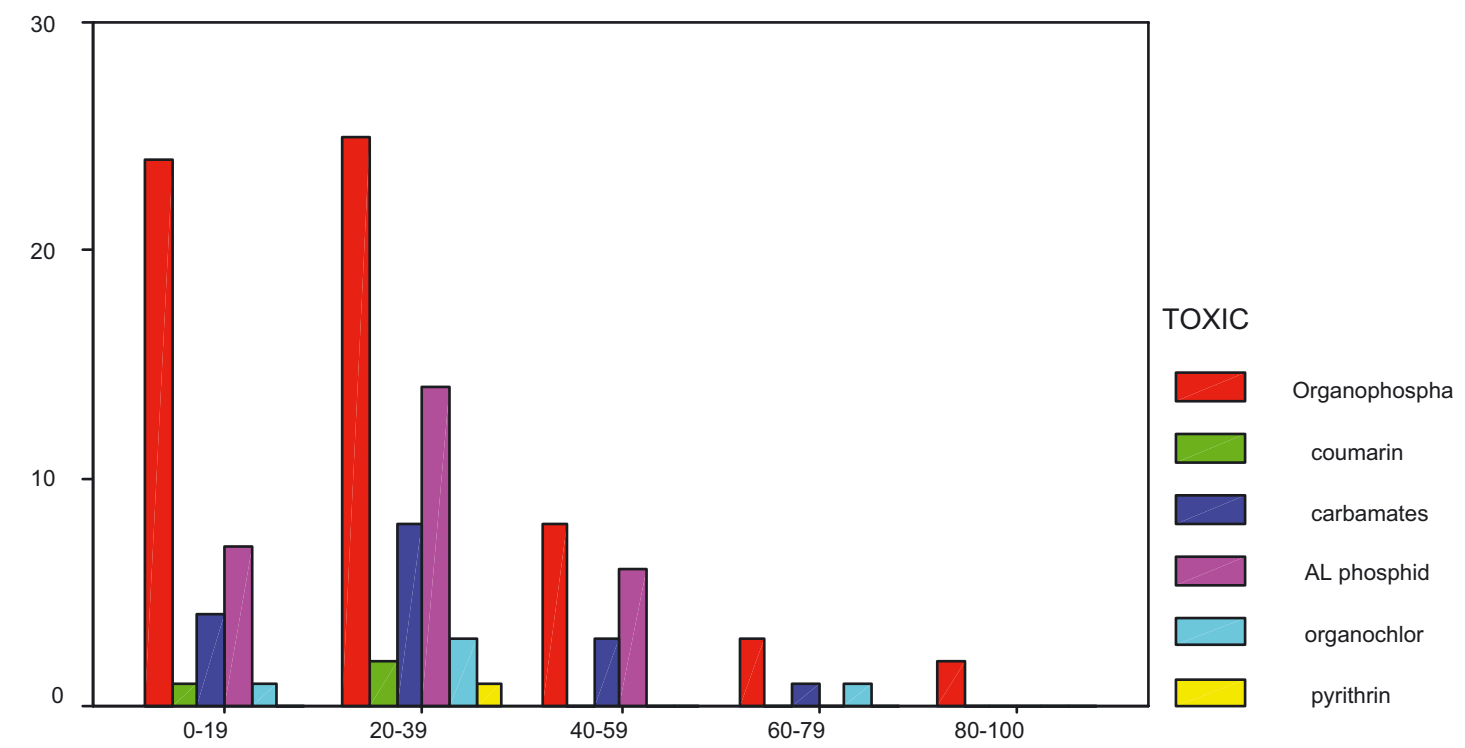

Fig. 1. Frequency of pesticides poisoning according to age.

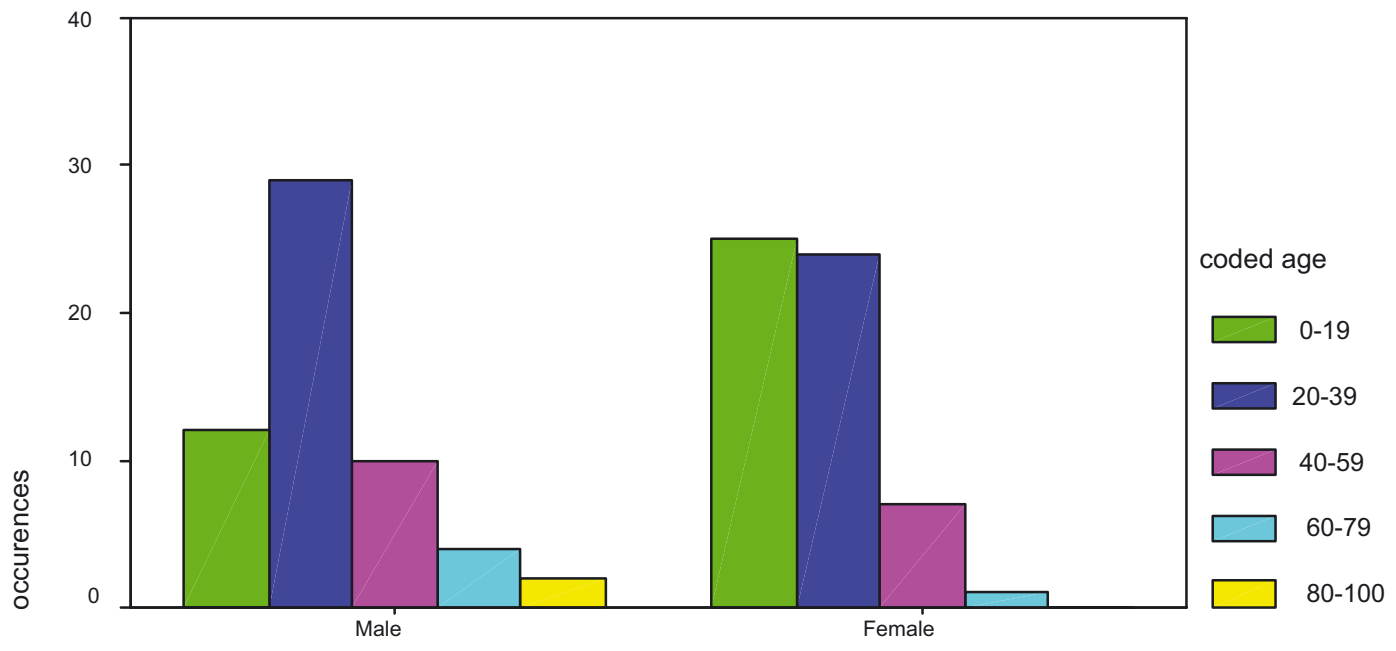

GENDER

Fig. 2. Frequency of pesticides poisoning according to gender.

most common method of suicide worldwide [1]. Young adult especially women are the most susceptible to be intoxicated by pesticides especially in age group 20-30 years old. Some studies mentioned the same result which confirms our results [15]. The age of men (20-39) is connected to the use of pesticides in occupational environment and professional activities.

The high percentage of uncertain cases could be explained by the lack of information. In fact, the autopsy report which content information about circumstance of mortality was not received in all cases. Organophosphorus and carbamates pesticides were the main pesticides encountered in agreement with other studies coming from Mediterranean countries [12].

The methods of analysis used in the laboratory allow to identify in a clarify way the toxic involved in pesticides poisonings. However the interpretation adopted for the results is based on the family of pesticides and does not take into account any toxic matter. This could be explained by the lack of legislative texts regulating the domain of Forensic toxicology and specifying the results to be given.

Morocco is an agricultural country and the use of pesticides is essential in this domain. The availability of pesticides and the young person age increase the poisoning frequency. As well as the particularity of the Moroccan farmers who are for the greater part illiterates what exposes them to occupational accidents. We also note the part of accidents at home. The majority of accidents at home are due by women and it was voluntary that may explain the small difference between men and women intoxications. Aluminum phosphide (phostoxin ${ }^{\circledR}$ ) represents the second cause of mortality in spite of the reglementation of pesticides in Morocco [16]. However, rodenticides 


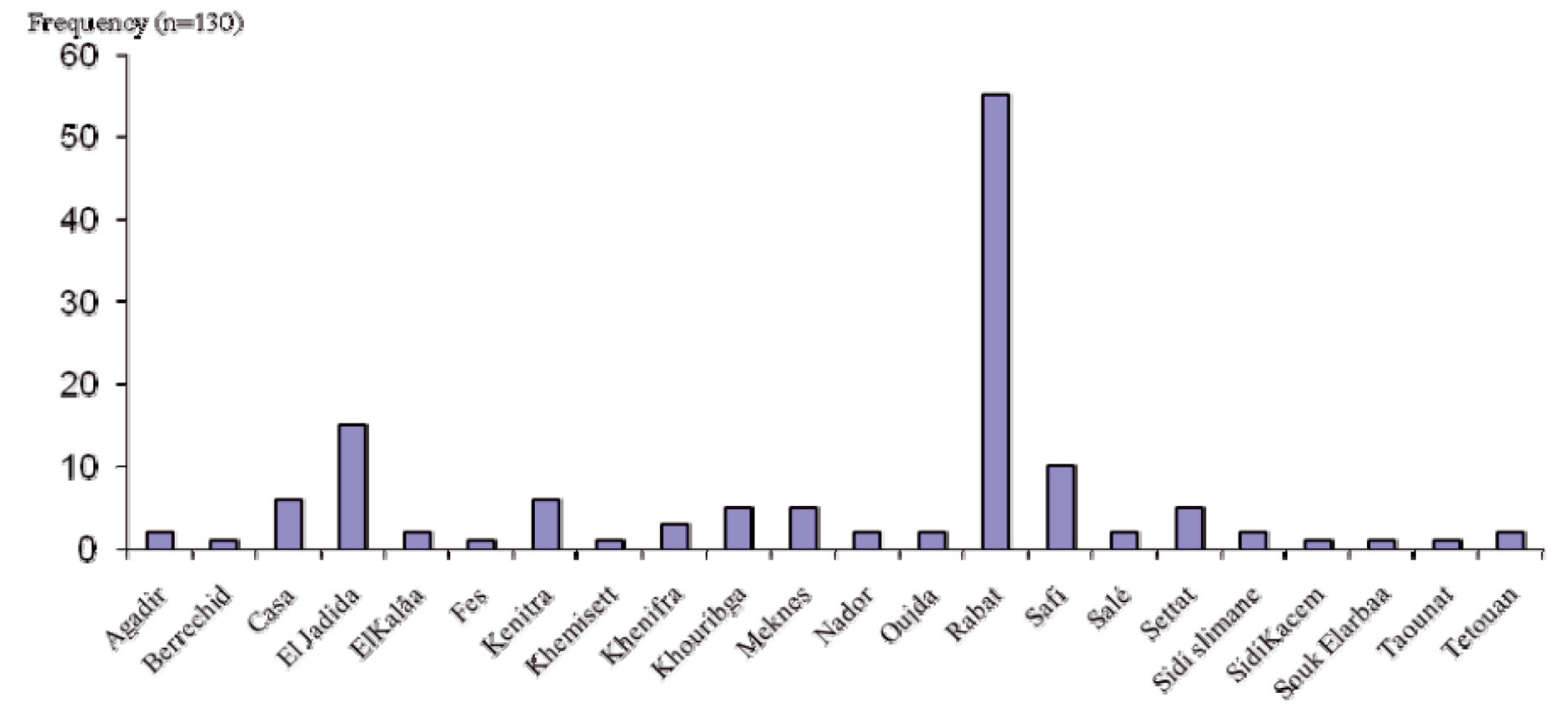

Fig. 3. Fatal pesticides poisoning spatial distribution.

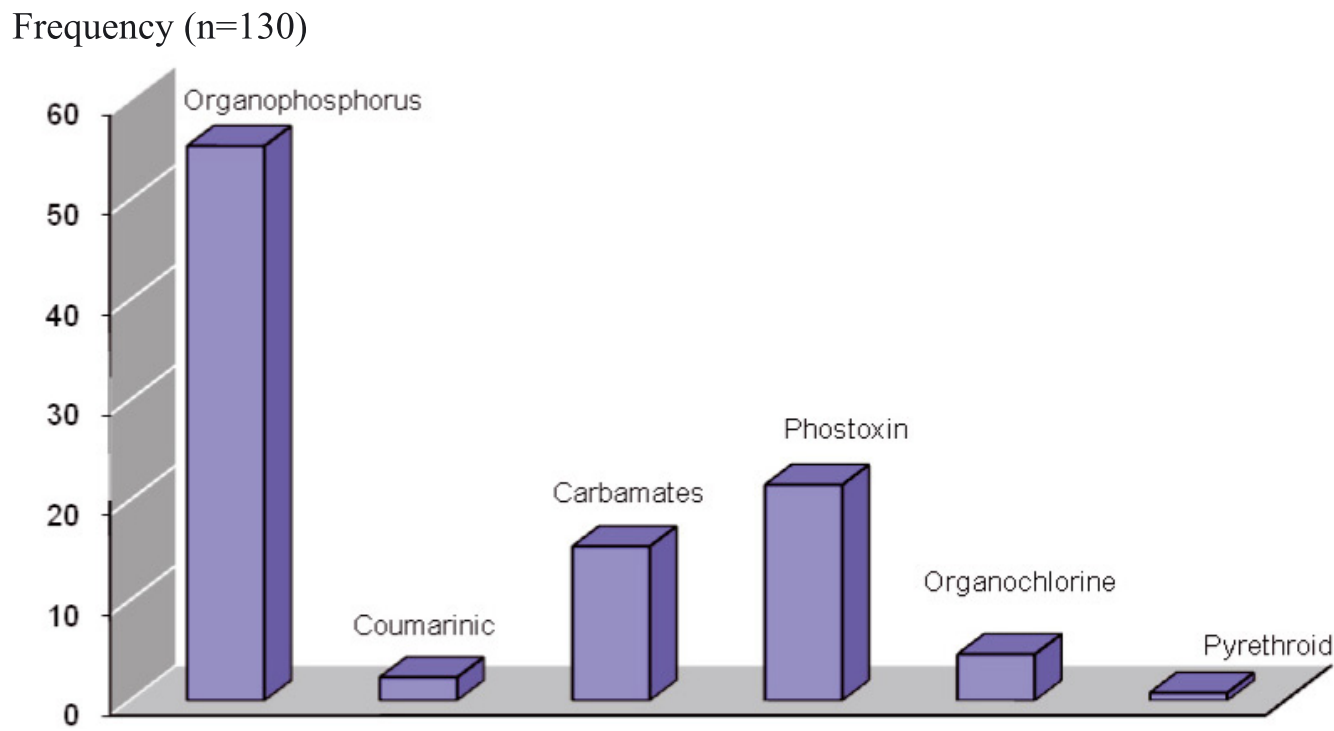

Fig. 4. Fatal pesticide poisoning according to type of toxic.

poisoning remains less important than in certain developing countries like India. The cases of organochlorine poisoning found are essentially related to the antiacridien fight.

\section{Conclusion}

Insecticides are the most important agent in fatal pesticides poisoning. In spite of the rules of pesticides in Morocco and its engagement in many conventions and agreement about pesticides like the agreement of Stockholm on persistent organic pollutants Pop and that of Rotterdam, there is a lack of application and control of those rules. Therefore, more stringent legislation and reforcmemnt inspecting or controlling sale and distribution of those pesticides needed in order to prevent the poisoning.

\section{References}

1. Testud F, Grillet JP. Insecticides organophosphorés, carbamates, pyréthinoides de synthèse et divers. EMC. Paris : Elsevier Masson, 2007 : 16-059-C-10.

2. Gunnel D, Eddleston M, Michael RP, Konradsen F. The global distribution of fatal pesticides self poisoning: systematic review. BMC Public Health. 2007; 7: 357.

3. Lacassie E, Marquet P, Gaulier JM, Dreyfuss MF, Lachatre G. Sensitive and specific multiresidue methods for determination of pesticide of various classes in clinical and forensic toxicology. Forensic Sci Int. 2001; 2: 116-125.

4. Bertolote JM, Fleischmann A, Butchart A, Besbelli N. Suicide attempts and pesticides: a major hidden public health problem. Bull World Health Organ. 2006; 84: 260. 
5. Ellenhorn MJ, Schonwald S, Wasserberger J. Ellenhorn's medical toxicolgy: diagnosis and treatement of human poisoning. 2nd ed. Maryland : Williams \& Wilkins, 1997.

6. Jeyararnum J. Acute pesticides poisoning: a major global health problem. World Health Stat Q. 1990; 43: 139-144.

7. Abdullat EM, Hadidi MS, Al-Nsour TS, Hadidi KA. Agricultural and horticultural pesticides fatal poisoning. The Jordanian experience 1999-2002. J Clin Forensic Med. 2006; 13: 304-307.

8. Soltaninejad K, Faryadi M, Sardari F. Acute pesticide poisoning related deaths in Tehran during the period 2003-2004. J Forensic Leg Med. 2007; 14(6): 352-354.

9. Casey P, Vale JA. Deaths froms pesticides poisoning in England and Wales: 1954- 1989. Hum Exp Toxicol. 1994; 13: 95-101.

10. Vougiouklakis T, Vassiliki Md, Boumba A, Mitselou A. Fatal poisoning in the region of Epirus, Greece, during the period 1998-2004. J Clin Forensic Med. 2006; 13: 321-325.

11. Eddleston M, Phillips MR. Self poisoning with pesticides. $\mathrm{Br}$ Med J. 2004; 57: 247-254
12. Vougiouklakis T, Boumba VA, Mitselou A, Peschos D, Gerontopoulod K. Trends in suicide mortality in the deprived region of Epirus (North-Western Greece) during the period 1998-2002. Med Sci Law. 2005; 45: 39-46.

13. Nesime Y, Lokman B, Akif IM, Gurol C, Basar C, Mustafa K. Acute pesticide poisoning related deaths in turkey. Vet Hum Toxicol. 2004; 46: 342-344.

14. Manuel C, Gunnell DJ, Van der Hoek W, Dawson A, Ishka K, Wijertane, Konradsen F. Self poisoning in rural Sri Lanka: small area variations in incidence. BMC Public Health. 2008; 8: 26.

15. Teixeira H, Proenca P, Alvarenga M, Olveira M, Marques EP, Vieira DN. Pesticide intoxications in the Centre of Portugal : three years analysis. Forensic Sci Int. 2004; 143: 199-204.

16. Dahir $\mathrm{N}^{\circ} 1-97-01$ du 12 ramadan 1417 (21 janvier 1997) portant promulgation de la loi $\mathrm{N}^{\circ} 42-95$ relative au contrôle et à l'organisation du commerce des produits pesticides à usage agricole. 